\title{
O historiador, o ensino de História e seu tempo (Notas sobre a problemática da Ditadura no Brasil - 1964/1985)
}

\author{
The historian, the teaching of history and his time \\ (Notes on the problems of dictatorship in Brazil - 1964/1985)
}

Marcos Silva*

\begin{abstract}
RESUMO
ABSTRACT

Este artigo reflete sobre relações entre This article reflects on relations between historiadores e seu tempo. O texto analisa historians and their own time. The text essas relações como tema (historiadores analyses these relationships as subject (some estudam temas contemporâneos deles) e como historians studying their own time) and as referência indireta (historiadores estudam indirect allusions (some historians studying diferentes períodos e usam recursos técnicos e different periods and use contemporary the teóricos de sua contemporaneidade). O technical and theoretical means). The paper trabalho discute ainda a importância do Ensino also discusses how important of the education para esses estudos. A experiência da ditadura for these studies. The experience of the no Brasil (1964/1984) e os esforços dictatorship (1964/1984) and the democratic democráticos do país (de 1985 aos nossos dias) efforts of the country (1985 to present day) in são os principais processos históricos evocados Brazil are the main historical processes evoked na discussão. in the discussion.
\end{abstract}

PALAVRAS-CHAVE: Historiador; Ensino de KeYwORDS: Historian; History teaching; História; Contemporaneidade; Ditadura Contemporary time; Dictatorship (1964/1984); (1964/1984); Brasil.

Brazil.

O francês Jules Michelet, em meados do século XIX, falou sobre a ida dos historiadores aos arquivos e seu contato com documentos antigos como um encontro com os mortos, que os trazia de volta à vida (MICHELET, 1869, comentado por CERTEAU). Essa metáfora lembra que os Historiadores, quando estudam os passados mais remotos, transformam-nos duplamente em presente: o presente original daqueles documentos (quando o que hoje é passado era contemporâneo de seus sujeitos) e o presente de sua interpretação atual. Dessa forma, o trabalho do Historiador, traduz duas vezes os tempos passados como temporalidades contemporâneas, evidenciando o conteúdo de vida humana nos temas que ele estuda e em seus procedimentos.

* Livre Docente e Professor Titular da Universidade de São Paulo (USP) / Brasil).

Antíteses, vol. 2, n. 3, jan.-jun. de 2009, pp. 23-36

http://www.uel.br/revistas/uel/index.php/antiteses 
O pensamento histórico fala em contemporaneidade, de uma maneira mais imediata, como um período articulado às identidades experimentadas diretamente pelo Historiador e por seus leitores. Trata-se de pensar: este é meu tempo, este é o nosso tempo. Daí, a definição de marcos inaugurais da História contemporânea. Os marcos de contemporaneidade mais comuns do mundo dito ocidental têm sido a Revolução Francesa (1789), a Revolução Industrial (fins do século XVIII) ou, mais amplamente, as revoluções que se iniciaram no século XVII inglês, culminando com a "Revolução Gloriosa", e se prolongaram até ao final do século seguinte, englobando Europa e Américas (a Independência dos EEUU, 1776; a Independência do Haiti, 1804), com fortes desdobramentos no resto do mundo e um elenco de temas, personagens, acontecimentos, fontes (HOBSBAWN, 1979). Diferentes experiências históricas podem remeter a atos inaugurais particulares da contemporaneidade, em consonância com a interioridade nacional na História, como se observa nos casos da China, com o movimento patriótico de 1919 e a revolução dos anos 40, e dos EEUU, com a Guerra de Secessão, de 1864/1870 (CHESNEAUX, 1995).

No próprio ato de se designar um tempo como "meu" ou "nosso", existe uma marca de sujeitos de pensamento: esse tempo é contemporâneo para nós, nós assim o nomeamos em função de uma auto-identificação. $O$ critério de contemporaneidade, portanto, vai além de um recorte cronológico (de 1789 ou do fim do século XVII aos nossos dias, por exemplo), para atingir o anúncio de que falamos da História que nos diz respeito mais de perto, a História que, mesmo ultrapassando retrospectivamente nossas vidas biológicas, é considerada a constitutiva mais próxima delas.

Quando pensamos nesse ângulo da História contemporânea (o dos sujeitos que a enunciam e a assumem como diretamente deles), podemos retomar um tema do Filósofo italiano Benedeto Croce, sem necessariamente preservar o conjunto de suas conseqüências filosóficas e políticas: toda História é contemporânea (CROCE, 1964).

Em Croce, essa questão assume um teor tardo-hegeliano: toda História é contemporânea porque o Espírito a atualiza enquanto Razão (HEGEL, 1985). Sem permanecermos literalmente nesse horizonte croceano e hegeliano, vale lembrar que a contemporaneidade do historiador e de seus leitores sempre está presente em qualquer perfil de periodização ou interpretação de História que se 
construa. Mesmo um historiador factual, cioso dos riscos de anacronismo e desejoso de recuperar um puro passado, como o francês Fustel de Coulanges, no final do século XIX, só exerceu essa abordagem a partir de uma contemporaneidade do conhecimento que elaborou tal fazer teórico e técnico (FUSTEL DE COULANGES, 1893). Quando falamos, como historiadores, no século XXI, de dinastias egípcias na Antiguidade, heresias da Europa medieval ou quilombos da América portuguesa, tratamos, também, de nossa contemporaneidade, através de teorias, técnicas e horizontes políticos e gerais próprios ao nosso tempo -abordagens demográficas ou lingüísticas, apelos à Informática e à datação via recursos físico-químicos, reivindicações de movimentos e grupos sociais organizados da atualidade, como é o caso do Feminismo, que serviu de inspiração para a História das Mulheres, ou dos Afro-descendentes, que cobraram novos olhares sobre a História de sua terra ancestral.

Daí, todo conhecimento histórico abordar, simultaneamente, um tempo que lhe serve de referencial (diferentes passados) e um tempo que é seu espaço de problematização e debate (o presente do Historiador e de seus leitores) (CHESNEAUX, 1995; SILVA, 2003).

Essa situação não pode servir de álibi para o silêncio historiográfico sobre o passado recente e o presente. Mesmo que a contemporaneidade esteja sempre integrada à abordagem histórica a respeito de qualquer período da experiência humana, declarado nosso a partir dos critérios de escolha e interpretação adotados, é muito importante garantir que o Historiador também aborde referenciais temáticos mais imediatos de seu tempo, participando dos debates com outros profissionais e sujeitos da sociedade civil que discutam esses assuntos.

Ao mesmo tempo, vale lembrar que a dimensão contemporânea de todo conhecimento histórico não pode ocultar a faceta inter-contemporânea desse campo de saber: se o historiador conduz consigo, incontornavelmente, seu tempo quando aborda qualquer outro período, este último foi um presente para si mesmo, aberto a diferentes compreensões da temporalidade, do passado, do presente e do porvir.

Por este motivo, a compreensão de que a contemporaneidade aborda uma História se fazendo remete para a definição de toda temporalidade histórica como experiência em aberto, que recebeu determinadas configurações (sempre provisórias) a partir das relações de poder entre os grupos sociais em relação. 
Isso evoca a importância dos múltiplos projetos sociais presentes nas experiências humanas estudadas pelos historiadores, articuláveis aos projetos sociais de seu presente através de múltiplas mediações (BENJAMIN, 1986).

A contemporaneidade, portanto, é mais que um campo temático ou um recorte de periodização. Ela é parte constitutiva do próprio conceito de História e se apresenta, teimosamente, até para quem procura fugir dela, abrigando-se em passados mais ou menos remotos e idealizados. As contemporaneidades atacam esses fugitivos de múltiplos lados, quer isso lhes seja consciente ou não.

Discutirei algumas dessas questões sobre o Historiador e seu tempo em relação a uma experiência da História política que marcou e marca profundamente o tempo que eu vivi e vivo: a Ditadura civil-militar brasileira, de 1964 a 1985.

Parto de uma afirmação aparentemente banal: houve uma ditadura no Brasil, a partir de 1964 (SILVA, 2006).

A necessidade de reafirmar que a ditadura brasileira já era ditadura em 1964 responde a uma tendência predominante, hoje em dia, nas discussões sobre aquele período. Tem sido habitual falar em uma ditadura propriamente dita no Brasil, quando muito, a partir de 1968, e não somente nos estudos especializados, mas também na memória social (opinião pública, Imprensa) dedicada ao tema. A placa de inauguração do paulistano Centro Cultural Maria Antonia, que pertence à USP, coloca 1968 como ponto de partida do regime. O Ato Institucional $\mathrm{n}^{\mathrm{o}}$. 5 (AI-5) foi implantado em dezembro desse ano, e a ditadura ficou muito mais grave a partir daquele momento. É preciso destacar, todavia, que, em 1964, a ditadura já começara ditatorialmente, e não de uma forma "discreta", "democrática" (o jornal Folha de São Paulo cunhou o termo "ditabranda" em 2009) nem como o jornalista Elio Gaspari falou mais recentemente, "envergonhada" (GASPARI, 200.): imaginemos o que ela faria se fosse desavergonhada! (SILVA, 2005).

Um exemplo claro desse caráter inaugural da ditadura foi o que aconteceu com o comunista Gregório Bezerra, em Recife, episódio registrado por Gaspari. Nos dias da implantação do regime, ele foi amarrado num veículo e arrastado em público. Tratava-se de um ato de violência explícita, com o novo governo declarando a quem via aquilo: "eu sou uma ditadura". Afinal, nenhuma lei do país previa espetáculos dessa natureza, executados por agentes do governo. 
Apenas o arbítrio ditatorial podia "justificar" aquele ato.

Existiram personagens de destaque na ditadura, desde seu início, que eram cultos, refinados, falavam e escreviam muito bem. E que, por isso, justificavam sofisticadamente o que estavam fazendo, dizendo que agiam daquela maneira para impedir que João Goulart e seus aliados implantassem uma ditadura. São raciocínios patéticos: criar uma ditadura para impedir que outra ditadura fosse instaurada; transgredir a lei em nome da lei. Mas nem somente esses inventores do regime adotaram tal lógica enviesada. Hoje em dia, ouvimos de muitos Historiadores, Jornalistas e Cientistas Sociais o argumento de que a ditadura brasileira era branda, menos violenta do que as congêneres de outros países latino-americanos, como a Argentina e o Chile. Há mesmo quem ponha em dúvida seu teor ditatorial.

Esses argumentos de brandura, menor violência ou até não-ditadura, em meu entendimento, são equívocos muito graves. Às vezes, estão baseados em comparações estatísticas: no Brasil, existiram comprovadamente algumas centenas de mortes provocadas pela ditadura de 1964/1985 e no Chile ou na Argentina, milhares. A conclusão estabelecida por esses analistas é que nesses outros dois países, o processo ditatorial foi mais violento (e houve real ditadura) porque morreram mais pessoas, e que no Brasil, foi suave (ou nem chegou a ser ditadura) porque houve menos assassinatos diretos de opositores do regime. Esse é um ponto de vista abstrato, que deixa de lado a extrema violência de seres humanos, em qualquer número, serem mortos por motivos políticos. Não vejo sentido em fazer uma comparação apenas quantitativa nesse campo da experiência humana. Depois de Auschwitz, para retomar a clássica expressão de Theodor Adorno (ADORNO, 1986), crimes de estado são igualmente graves, mesmo que atinjam UMA pessoa.

Certamente, a quantidade nos assusta ainda mais, o fato de a violência governamental chegar àquele nível numérico (milhares de assassinatos políticos) é terrível, mas isso não significa que onde mataram menos pessoas, usando argumentos e caminhos similares, tenha sido menos terrível. Essa prática em menor escala é tão grave quanto os outros casos, pela ilegalidade, pela violência e pela incapacidade (ou negação) de se encaminhar a política através de meios revestidos de mínima dignidade, negociações entre as partes e preservação das vidas. Com todo respeito às vítimas das ditaduras no Chile e na 
Argentina, nós não podemos diminuir o sofrimento daqueles que morreram, de seus familiares e de seus amigos, no caso do Brasil, por serem em menor número. Sou totalmente contra essa comparação estatística e abstrata porque ela esvazia o significado tanto da dor pessoal quanto da experiência política de quem sofreu a ditadura brasileira e lutou contra ela. E não vejo em que ela pode servir de base para algum conhecimento sobre o tema.

Não existem ditaduras brandas. Na historiografia e na memória social brasileiras, persistiu, durante muito tempo, o mito da escravidão branda. Felizmente, ele foi criticado ao menos desde a década de 50 do século XX, principalmente a partir dos escritos de Roger Bastide e Florestan Fernandes (BASTIDE e FERNANDES, 1955; SCHWARCZ, 1998). Agora, nós assistimos à vigência do mito da ditadura branda. Considero importante deixar claro que a ditadura civil-militar do Brasil começou como ditadura em 1964, com seus representantes refinados, que falavam e escreviam bem. Humberto de Alencar Castelo Branco, Golbery do Couto e Silva, Ernesto Geisel, Carlos Lacerda, Antonio Delfim Netto, Roberto Campos e alguns outros nomes de destaque na ditadura brasileira eram homens eruditos (Delfim Netto continua a ser, pois está vivo). A cultura pessoal, todavia, não absolve ninguém de responsabilidades em relação a desmandos nem desdiz seu caráter ditatorial, quando é o caso.

É preciso superar, no plano do conhecimento, os argumentos que amenizam a experiência da ditadura. Ao mesmo tempo em que são mitos sobre o regime, são também reafirmações da memória que ele quis deixar de si mesmo. A ditadura brasileira de 1964/1985 se definiu, desde seu começo, como branda, como se nem fosse ditatorial, como muito discreta ou, na pior das hipóteses, atuante apenas por um período curto, dentro da lei, até poder "reorganizar" o país. Devemos repetir essas auto-definições indulgentes ou procurar explicar sua lógica auto-justificadora?

É importante, ao mesmo tempo, discutirmos essas questões políticas de uma maneira não demonizadora dos diferentes sujeitos em cena. São seres humanos, que têm projetos humanos, mesmo quando terríveis, como é o caso de quem torturou e matou. Não são projetos iguais, existem diferenças até entre os defensores da ditadura (nem todos eles torturaram e mataram), sem esquecer de quem criticava o regime. Prefiro, como opção política, os projetos de quem se opunha à ditadura e considero indefensáveis crimes contra a 
humanidade, como torturas e assassinatos políticos. Agora, é preciso explicar essas situações, não basta rejeitar nem acolher seus termos. Se transformarmos os sujeitos da ditadura em demônios, perderemos a oportunidade de cobrar suas responsabilidade (humanas) nos campos da Política e da Ética. Afinal, demônios freqüentam outras esferas da realidade, não sentem culpa nem têm perspectivas de mudar.

Vários setores da Imprensa e também da Pesquisa Acadêmica assumem muitos daqueles argumentos derivados da memória ditatorial, hoje em dia. Nem falam tanto que João Goulart era comunista ou algo parecido e sim que ele era desinteressado da política, pouco ativo e sem propostas. Mais um raciocínio patético: derrubam-se presidentes por serem desinteressados de política e sem propostas ou para impedir que seus interesses e propostas sigam adiante?

O exemplo mais evidente dessa vertente interpretativa é a série de livros As ilusões armadas, do jornalista Elio Gaspari, já mencionada. Mas também há alguns historiadores e cientistas sociais que reproduzem esses argumentos. Maria Hermínia Tavares de Almeida e Luís Weis, no quarto volume da influente série de livros História da vida privada no Brasil (Contrastes da intimidade contemporânea), reafirmam que o período de 1964 a 1968 foi brando, que os presidentes da república nesses anos concederam liberdades para a população (ALMEIDA e WEIS, 1998), configurando mais um contra-senso: ditadores garantem liberdades? No período governamental de Castelo Branco e na primeira metade do governo de Artur da Costa e Silva, antes do AI- 5 , havia muitos movimentos sociais, mas não porque esses governantes concedessem algo para eles: parcelas da população ocupavam tal espaço, preservando tradições de luta então ainda recentes e fortes. Nada era dado, era um direito duramente conquistado. E o governo Costa e Silva culminou com o AI-5!

Muitos desses autores que reproduzem a auto-legitimação da ditadura estudam diversificados documentos de época e lidam com teorias complexas. No entanto, não estão fazendo uma crítica adequada àquela memória. Pelo contrário, eles repetem o que a ditadura queria que fosse pensado a seu respeito. Cientistas sociais, Jornalistas e Historiadores, em meu entendimento, precisam refletir criticamente sobre argumentos e não apenas endossar o que diferentes sujeitos afirmaram sobre suas ações. Quando fazem o contrário, transformam-se em porta-vozes, muitas vezes involuntários, daqueles sujeitos. 
Um outro exemplo dessa ausência de crítica é a própria imagem de que a ditadura foi militar e ponto. É importante destacar também a responsabilidade civil na ditadura, desde sua implantação e até seu fim. No momento inicial do regime, havia lideranças como Carlos Lacerda (jornalista) e Magalhães Pinto (banqueiro), além de legitimação do que estava sendo feito por grandes órgãos de Imprensa, casos de $O$ Estado de S. Paulo e Correio da manhã (os dois jornais entrariam em conflito com a ditadura, posteriormente). Depois, em plena vigência ditatorial, houve outras figuras civis expressivas no aparelho governamental, na Imprensa e noutros setores da sociedade: Roberto Campos (economista), Delfim Neto (idem), Paulo Maluf (empresário) etc.

Além disso, durante o período, não foram apenas os governantes e seus auxiliares diretos que agiram no espaço da Política. Muitos dos escritos sobre o assunto enfatizam excessivamente o papel dos presidentes e de algumas lideranças governamentais a eles associadas, concentrando os rumos da ditadura nessas figuras. É evidente que tais personagens devem ser discutidos, mas enquanto os presidentes da república e seus auxiliares agiam, havia uma sociedade em movimento, rechaçando ou apoiando o regime. Elio Gaspari deu uma grande ênfase para o projeto de "abertura política" a partir do governo Ernesto Geisel como uma proposta desse presidente (GASPARI). É preciso levar em conta que alguns setores da sociedade brasileira já estavam se mobilizando, se movimentando e realizando diferentes manifestações contra rumos da ditadura desde o início do regime. Não foi apenas aquele indivíduo que se revelou visionário e promoveu, isoladamente, a mudança de rumos na política. Ele teve uma atitude sagaz e inteligente ao começar a preparar um desfecho do processo favorável aos defensores da ditadura. Agora, dizer que isso apenas saiu de sua cabeça porque ele era assim, queria assim, por um temperamento pessoal e político ou por um "projeto democrático da ditadura" (outra contradição de termos) desde seu início, ao redor de Castelo Branco, para mim, é mais um grande equívoco de interpretação.

A ditadura civil-militar de 1964/1985 procurava controlar e, em relação a alguns sujeitos, anular a sociedade civil. Mas essa sociedade se mexia por vários caminhos: para garantir que uma peça teatral fosse exibida ou que uma música fosse liberada em audição pública, para criar associações de bairro ou denunciar problemas, como salários e carestia. Havia, também, a ação dos advogados: 
durante a ditadura, o plano da lei, no Brasil, foi praticamente suspenso (uma leitura do $\mathrm{AI}-5$ é esclarecedora a esse respeito); as garantias legais passaram a existir de uma maneira absolutamente frágil, pois o poder executivo podia suspender qualquer direito, inclusive tolhendo a ação de juízes. Todavia, muitos advogados lutavam para localizarem presos e para garantirem seus direitos (o tema figura no texto de ALMEIDA e WEISS). Tais lutas, junto com outras, expressaram a sociedade civil se rearticulando e se reorganizando. Por outro lado, é impossível negar que outros setores da mesma sociedade civil apoiavam o regime.

É preciso, portanto, ampliar a discussão sobre a experiência ditatorial. A ditadura não "caiu do céu". Setores da sociedade brasileira implantaram e mantiveram o regime, às vezes de forma auto-destrutiva. Outros setores lutaram contra aquele estado de coisas. É importante entender a ditadura como uma experiência social, tanto no sentido de ser sustentada quanto no de ser derrubada. Ela não foi apenas política institucional formal. E não saiu de cena sem deixar vestígios.

Discutir essa ditadura é muito importante, mas os períodos não ditatoriais, como nosso passado mais recente e o presente, também devem ser debatidos criticamente pelos Historiadores. Além de torturas e prisões, o regime ditatorial praticava extrema violência em relação aos salários, arrochava-os de maneira avassaladora para amplos setores da sociedade, com sérias conseqüências nos planos de Saúde e Educação. O regime acabou, mas hoje temos aquele e um outro tipo de violência sobre os salários: o desemprego. E vemos novos desmontes de cidadania, em nome do mercado.

As ditaduras se encerram em termos da política institucional (passa a haver eleições regulares, a Constituição é quase sempre respeitada, a censura é suspensa), mas também deixam pesados resquícios: a questão do desemprego, a infância, a juventude e a velhice dos pobres abandonadas, a destruição de setores públicos de Saúde e de Educação são alguns exemplos disso. Temos uma série de problemas que começaram ou se agravaram no período ditatorial e que continuam até hoje. Em contrapartida, a memória sobre a "modernidade" da ditadura se consolida, como se esses problemas fossem de um presente absoluto e aquele regime representasse um exemplo de racionalidade administrativa.

Isso nos leva a duas perguntas: Qual a democratização que se 
experimentou e experimenta, no Brasil, desde 1985? Como a memória sobre a ditadura se articulou, a partir de então?

A melhor introdução a esse tema foi oferecida por Elizabete Teixeira, viúva de João Pedro Teixeira (líder na luta pela terra, assassinado em 1962), no filme Cabra marcado para morrer, de Eduardo Coutinho (COUTINHO, 1985). Encerrando suas rememorações sobre a ditadura, nas últimas cenas do filme, Elizabete indaga desafiadoramente: que democracia é essa, onde os filhos dos pobres não têm as mesmas oportunidades de vida que os filhos dos mais abastados têm?

Entendo essa pergunta de Elizabete como uma cobrança de conteúdo em relação à democracia, e não como negação dessa via política: é preciso que sua pauta inclua igualdade de oportunidades, melhoria nos padrões de vida dos pobres, esperança para a maioria da população. Nesse aspecto, a democracia estabelece permanentes tensões com o universo de hierarquias sociais apoiadas no preconceito e na violência permanente em relação aos menos poderosos. $\mathrm{Na}$ cobrança de Elizabete, democracia é ponto de partida para novas conquistas sociais e não panacéia universal para todos os males.

Outra lembrança que me ocorre, para caracterizar a experiência da democracia dos últimos 20 anos, é o filme musical Quando o carnaval chegar, de Cacá Diegues (DIEGUES, 1972): o carnaval chega e a vida continua cheia de limitações e problemas; existe o perigo de acharmos que é tudo sempre igual, que ditadura e democracia são a mesma coisa.

Em 1985, a ditadura civil-militar acabou. A memória que restou desse fim enfatiza:

1) A Campanha pelas eleições diretas para Presidente, em 1984.

2) A eleição indireta (dentro das regras ditatoriais, portanto) de Tancredo Neves, no mesmo ano.

3) A agonia e morte do presidente eleito, em 1985.

4) A posse e o governo de José Sarney, até um ano antes líder do partido de apoio à ditadura -o PDS-, em 1985.

Se a Campanha pelas eleições diretas para presidente da república se notabilizou como grande mobilização nacional, é preciso registrar sua derrota. A eleição de Tancredo Neves foi uma perda para a ditadura (o candidato desta era Paulo Maluf), mas sua realização no Colégio Eleitoral se constituiu em vitória do 
regime que se encerrava. Tancredo Neves, eleito, representava esperanças difusas de novos tempos, porém sua internação hospitalar antes da posse, seguida de agonia e morte, foi uma profunda frustração. E a chegada de José Sarney à presidência parece episódio em comédia de erros: ele pretendera ser candidato ao cargo pelo partido situacionista da ditadura (PDS), e findou preterido em benefício de Paulo Maluf, forte motivo para sua adesão à "Frente Liberal" que, em 1984, uniu dissidentes do PDS aos peemedebistas.

A memória instituída sobre o fim da ditadura brasileira excluiu, desde então, a presença de movimentos sociais que reivindicavam, na superação do regime, alterações nas pautas governamentais, mudanças no atendimento a demandas dos setores majoritários da população, como conquistas desses setores -quer dizer, como manifestações de seu poder, como direitos. Não é ocasional que a memória dominante sobre o fim daquele regime tenha apagado a existência de um movimento contra o desemprego, de seu acampamento em São Paulo, no Parque Ibirapuera, e de sua caminhada de protesto à sede do governo paulista (Palácio Bandeirantes), que culminou na derrubada de grades desse edifício.

Apesar das frustrações que a democratização trouxe, reforçadas por escândalos e denúncias sobre governantes e políticos, vale realçar uma modesta conquista da sociedade brasileira nas últimas décadas: a crítica e a discordância políticas quase sempre são criminalizadas. Isso pode parecer banal, hoje, mas é um direito duramente garantido e que, durante a ditadura, era tratado como traição e crime. E é um direito que pode ser ampliado para que não se apele à polícia contra movimentos sociais.

É para melhor conhecer essas pequenas conquistas e as grandes frustrações sofridas pela população que o trabalho do Historiador com sua contemporaneidade pode ajudar tanto aos profissionais dessa área específica de conhecimento quanto aos cidadãos em geral -e o ensino desempenha função primordial no último caso.

Se o campo geral da pesquisa histórica enfrenta barreiras para o debate sobre passado recente (ditadura de 1964/1985, lutas pela democracia) e presente (a democracia realmente existente e seus escandalosos limites) em nosso país, o quadro se torna ainda mais difícil no universo do ensino, malgrado sua primordial importância para o conjunto da população: é a única 
oportunidade de contato sistemático com esse mundo de saberes para a maioria das pessoas, uma vez que poucas delas poderão optar profissionalmente por serem historiadores. Os debates mais recentes sobre saber escolar apenas começam a esboçar uma reação à tendência fortemente parasitária de se caracterizar o ensino de História e demais campos de conhecimento como repetidor automático de conquistas de saber que foram elaboradas noutras esferas: universidade, arquivo, biblioteca, museu, laboratório etc.

Não se trata, é claro, de opor a escola fundamental e média à universidade e a outras instituições similares de alta pesquisa nem de supor que inexistam relações entre esses espaços de saber desde sempre -formação dos docentes de ensino fundamental e médio, produção de livros didáticos ou não que eles consomem junto com seus alunos, congressos e cursos oferecidos como formação permanente etc. Faz-se necessário, todavia, restaurar ou até garantir inauguralmente uma altivez intelectual e política da escola destinada a crianças e jovens e de seus docentes, altivez muito difícil diante de reiteradas desvalorizações sociais desse universo no Brasil. Junto com as conquistas clássicas e justas de salários, instalações e equipamentos -ainda tão sacrificados entre nós-, é preciso valorizar também os professores dessas escolas como pensadores de suas áreas de trabalho.

A escola fundamental e média é um espaço onde o estado do conhecimento histórico (e de outros campos de saber) pode ser apresentado de forma reflexiva pelo professor a crianças e adolescentes. Isso significa que os docentes têm a opção de se relacionarem de forma crítica com a produção erudita gerada sobre aqueles temas e problemáticas de conhecimento por outras instâncias de saber, chegando a novas erudições. No caso específico de História, tal relacionamento passa pelo contato permanente e crítico de professores e alunos com a Historiografia, é claro, e também com a Memória Social elaborada no Brasil sobre ditadura e democracia -exemplos aqui abordados: discursos governamentais e partidários, vozes da Imprensa, produções artísticas (cinema, literatura e outras linguagens) etc.

As relações da Historiografia erudita mais habitualmente reconhecida (gerada em universidades, arquivos, museus e instituições similares) com a Memória Social ainda se revelam freqüentemente limitadas. É o que se observa no prestígio das análises que reiteram vozes dominantes, caso de Gaspari no 
campo da memória jornalística (GASPARI). A retomada de vozes dominadas movimentos sociais, por exemplo- pode ser um gesto de justiça mas não é necessariamente uma superação daquela outra perspectiva, uma vez que essas últimas memórias às vezes preservam muitos aspectos da outra. Observa-se, por exemplo, uma grande ênfase do cinema brasileiro sobre a memória da ditadura como momento sofrido de opressão e lutas. Se isso é uma conquista contra silêncios políticos e também historiográficos, contribui, simultaneamente, para outros silêncios políticos e historiográficos: o presente democrático é destituído de outras opressões e lutas? No mesmo exemplo dos filmes sobre a ditadura, observa-se grande ênfase nos grupos de luta armada como núcleos privilegiados de resistência ao regime: então, quem não participou desses grupos nada fez de crítico diante daquela situação nem merece nossa atenção?

Junto com isso, o debate sobre tal universo de temas e problemas de conhecimento convida o docente (como já o fizera em relação ao pesquisador acadêmico) a refletir sobre relações e limites entre Ciência e Política. A clássica resposta weberiana -vocações diferentes (WEBER)- se revela, depois de Auschwitz e Hiroshima/Nagasaki, muito insuficiente: dá para sustentar que aquelas esferas não se penetram reciprocamente o tempo todo? Mas isso não é solução: mesmo se percorrendo sempre, Ciência e Política não se equivalem simplesmente; conhecer História não é sinônimo de fazer legítimas opções políticas. É muito importante, no espaço do saber histórico -inclusive em sua dimensão de cultura escolar- deixar explícitas as dimensões de operação historiográfica: pesquisa documental, sistematização analítica dos documentos e escrita (CERTEAU).

Nesse sentido, o saber histórico produzido em diferentes espaços de reflexão (a academia, o arquivo, o museu, a escola) pode manter sua densidade teórica e técnica, sem supostamente sair da cena social e política. Porque sair efetivamente, ele nunca sai...

\section{Bibliografia}

ADORNO, Theodor. A Educação depois de Auschwitz. IN: COHN, Gabriel (Org.). Theodor Adorno. São Paulo: Ática, 1986, pp. 33-45. (Grandes Cientistas Sociais - 54).

ALMEIDA, Maria Hermínia Tavares de e WEIS, Luís. Carro zero e pau de arara-A oposição de classe média à ditadura militar. IN: SCHWARCZ, Lilia 
(Org.). Contrastes da intimidade contemporânea. São Paulo : Companhia das Letras, pp 319-409. (História da vida privada no Brasil - 4).

BASTIDE, Roger e FERNANDES, Florestan. Relações sociais entre brancos e negros em São Paulo. São Paulo: UNESCO, 1955.

BENJAMIN, Walter. Sobre o conceito de História. IN: Magia e Técnica, Arte e Política. Tradução de Sérgio Paulo Rouanet. $2^{\mathrm{a}}$ ed. São Paulo: Brasiliense, 1986, pp. 222-232. (Obras escolhidas - 1).

CHESNEAUX, Jean. Devemos fazer tabula-rasa do passado? Sobre História e historiadores. Tradução de Marcos Silva. São Paulo: Ática, 1995.

COUTINHO, Eduardo. Cabra marcado para morrer. Rio de Janeiro: Globo Vídeo, 1985 .

CROCE, Benedetto. História, pensamento e ação. Tradução de Darcy Damasceno. Rio de Janeiro: Zahar, 1964.

DIEGUES, Carlos. Quando o carnaval chegar. Rio de Janeiro: Mapa Filmes, 1972.

FUSTEL DE COULANGES, Numa Dinis. Questions historiques. Paris: Hachette, 1893.

GASPARI, Elio. A Ditadura envergonhada. São Paulo : Companhia das Letras, 2002. (As ilusões armadas - 1).

HEGEL, Georg W. Lecciones sobre la Filosofia de la Historia. Tradução para o espanhol de José Gaos. Madri: Alianza, 1985.

HOBSBAWN, Eric. Era das revoluções. Tradução de Maria Tereza Lopes Teixeira e Marcos Penchel. $2^{\text {a }}$ ed. Rio de Janeiro: Paz e Terra, 1979.

MICHELET, Jules. L'Héroisme de l'esprit (1869). Comentado em: DE CERTEAU, Michel. A escrita da História. Tradução de Maria de Lourdes Menezes. Rio de Janeiro: Forense, 1982.

SCHWARCZ, Lilia. Cor e raça no Brasil. IN: SCHWARCZ, Lilia (Org.). Contrastes da intimidade contemporânea. São Paulo : Companhia das Letras, 1998, pp 173-244 (História da vida privada no Brasil - 4).

SILVA, Marcos. História - O prazer em Ensino e Pesquisa. $2^{\mathrm{a}}$ ed. São Paulo: Brasiliense, 2003.

. Jornalismo retrospectivo e quase-História: Imaginem se a ditadura fosse desavergonhada!. Resenha de $A$ ditadura envergonhada, de Elio Gaspari (São Paulo: Cia. das Letras, 2002). Revista ADUSP. São Paulo: ADUSP, 34: 8o/84, maio de 2005.

LTDE, 2006.

(Org.). Brasil, 1964/1968: A ditadura já era ditadura. São Paulo:

WEBER, Max. Ciência e política, duas vocações. Tradução de Leonidas Hegenberg e Octany Silveira da Mota. São Paulo: Cultrix, 1972.

Colaboração recebida em 23/06/2009. 